\title{
Polymer Adsorption on Iron Oxide Nanoparticles for One-Step Amino-Functionalized Silica Encapsulation
}

\author{
Lionel Maurizi, Alexis Claveau, and Heinrich Hofmann \\ Powder Technology Laboratory, Ecole Polytechnique Federale de Lausanne (EPFL), 1015 Lausanne, Switzerland \\ Correspondence should be addressed to Lionel Maurizi; lionelmaurizi@gmail.com
}

Received 19 March 2015; Revised 26 May 2015; Accepted 27 May 2015

Academic Editor: John Zhanhu Guo

Copyright (C) 2015 Lionel Maurizi et al. This is an open access article distributed under the Creative Commons Attribution License, which permits unrestricted use, distribution, and reproduction in any medium, provided the original work is properly cited.

\begin{abstract}
This paper presents an original method to obtain, in one step, core/shell nanoparticles grafted covalently with polymer and functionalized with amino groups. By combining polyvinyl alcohol (PVA) and silica precursors, we were able to obtain silicacoated and amino-functionalized iron oxide nanoparticles (SPIONs) cross-linked with PVA. We also showed that using silica and amino-silica precursors together significantly increased the amount of PVA covalently bonded to the SPION surface compared to using only silica precursors. This original and interesting method has high potential for the industrial development of biocompatible functionalized nanoparticles for targeting nanomedicine.
\end{abstract}

\section{Introduction}

Superparamagnetic iron oxide nanoparticles (SPIONs) are currently being developed for several applications, with greatly increasing roles in biomedical applications, because of their low toxicity $[1,2]$. Out of their many possible bioapplications, SPIONs could be used as contrast agents for detection in magnetic resonance imaging (MRI) [3-5], for cell labeling [6], in hyperthermia [7], or in regenerative medicine [8].

SPIONs are not stable under physiological conditions due to the reduction of electrostatic repulsion [9], which causes nanoparticle (NP) aggregation. To redisperse SPIONs in biological media, further surface modifications are needed. They can be coated with stabilizing agents [10-13] to improve, for example, their steric repulsion. Controlling the chemistry of the surface is a key challenge to develop and understand the biological interactions of NPs [14, 15]. Developing controlled, robust, reproducible, and up-scalable methods to synthesize biocompatible NPs with as few steps as possible is a key parameter that must be focused on in order to further develop the industrialization of nanomedicine [16-18]. Among the possible usable surface modifications, polyvinyl alcohol (PVA) can control the size of their aggregates and stabilize the SPIONs in high ionic strength media at a $\mathrm{pH}$ of around 7 $[19,20]$. PVA is commonly used in bioapplications because of its nontoxicity, variety of molecular weights, and good interactions with metal oxide nanoparticles [21-24]. However, even though PVA can effectively stabilize nanoparticles and its use is easy and up-scalable, this polymer is only adsorbed onto their surface, allowing uncontrolled PVA release during biointeractions [25], leading to reproducible problems.

Encapsulating SPIONs inside silica beads is another method to stabilize them [26]. This coating electrostatically stabilizes the SPION using negative charges [27]. The silica shell controls the aggregation of the SPIONs [28] and also protects the biological fluids from the uncertainty of chemical desorption or direct contact with a dissolution of iron oxide at the interface [29]. Silica shells containing SPIONs could also be functionalized in order to tune their charges, such as with amino groups [30-32]. Usually, encapsulating NPs with functionalized silica shells is either done in a low amount such as with an aerosol pyrolysis method [33] or emulsion process [34-36], or it is done using several steps with a classical sol-gel process and a functionalizing agent $[37,38]$. Coating SPIONs with silica is an important approach in the development of magnetic nanoparticles for both fundamental and technological applications. However, the scale-up and reproducibility of silica synthesis is not as easy as expected because of the influence of all the previously described reaction parameter. 
In this work, we proposed an original solution to modify, in one step, the surface of SPIONs in a controlled, reproducible, and up-scalable manner by combining the stabilizing properties of PVA and the characteristics of silica. Based on the improvement of a method previously presented [39], PVA was cross-linked onto SPIONs by the addition of silica precursors with and without amino groups. We demonstrated that combining classical silica and amino-functionalized silica precursors at a volume ratio of $3 / 1$ with PVA-coated SPIONs (PVA-SPIONs) allowed for an easier and better synthesis of core/shell silica/SPIONs with PVA covalently grafted onto their surface. These nanoparticles combined the stabilization advantages of PVA and the reproducibility approaches of silica shells. Furthermore, this method made it possible to obtain, in one step, nanohybrids that could be further functionalized as a result of the amino groups on their surface.

\section{Materials and Methods}

2.1. Chemicals. All of the chemicals not mentioned were of analytical reagent grade and were used without further purification and provided from Sigma-Aldrich Chemie $\mathrm{GmbH}$, Buchs, Switzerland. Tetraethyl orthosilicate (TEOS) at $>99 \%$ and (3-aminopropyl)triethoxysilane (APTES) at $>99 \%$ were also provided by Sigma-Aldrich and used as silica precursors. Ultrapure deionized water (Seralpur Delta UV/UF setting, $0.055 \mu \mathrm{S} / \mathrm{cm}$ ) was used in all of the synthesis and analysis steps. PVA-OH, Mowiol 3-85 (with a hydrolysis degree of $85 \%$ and a molecular weight of $12000 \mathrm{~g} / \mathrm{mol}$ ), was supplied by Kuraray Specialties Europe GmbH, Germany. Amino-PVA (A-PVA from 80000 to $120000 \mathrm{~g} / \mathrm{mol}$ ), M12, was supplied by ERKOL S.A., Tarragona, Spain (now Sekisui Specialty Chemicals Europe). MWCO $12-14 \mathrm{kDa}$ cellulose membrane dialysis tubing was used for dialysis.

2.2. Synthesis of Iron Oxide Nanoparticles. SPIONs were synthesized following a classical coprecipitation protocol described in more detail elsewhere [40, 41]. Ferric and ferrous solutions at a molar ratio $\mathrm{Fe}^{\mathrm{II}}: \mathrm{Fe}^{\mathrm{III}}(1: 2)$ were mixed in ammonia solution for $2 \mathrm{~min}$. Then, the suspension was magnetically sedimented under a magnet and washed with water until the $\mathrm{pH}$ reached 7. The SPIONs were then oxidized with $\mathrm{HNO}_{3}$ and $\mathrm{Fe}\left(\mathrm{NO}_{3}\right)_{3}$ under reflux for $1.5 \mathrm{~h}$ and again magnetically sedimented, washed with water, and dialyzed against $\mathrm{HNO}_{3} 10 \mathrm{mM}$ for 3 days by changing the solution every $12 \mathrm{~h}$. The suspension was finally centrifuged at $30000 \mathrm{G}$ for $15 \mathrm{~min}$, and the particles in the supernatant were gently poured to obtain the final suspension of SPIONs at $\mathrm{pH} 3$ and a concentration of $10 \mathrm{mg}_{\mathrm{Fe}} / \mathrm{mL}$, which was kept at $4^{\circ} \mathrm{C}$ until used.

2.3. PVA Surface Modification of SPIONs. The surface modification of the SPIONs was conducted as previously described $[20,25]$. PVA-OH was dissolved at $80^{\circ} \mathrm{C}$ for $20 \mathrm{~min}$ in water to obtain a solution at $100 \mathrm{mg}_{\mathrm{PVA}-\mathrm{OH}} / \mathrm{mL}$. A-PVA was also dissolved in water under reflux for $40 \mathrm{~min}$ to obtain a solution at $20 \mathrm{mg}_{\mathrm{A}-\mathrm{PVA}} / \mathrm{mL}$. The PVA-coated SPIONs were fabricated by mixing 10 volumes of the SPION suspension $\left(10 \mathrm{mg}_{\mathrm{Fe}} / \mathrm{mL}\right)$ with 9 volumes of the PVA-OH solution and 1 volume of the A-PVA solution. The suspension was kept at $4^{\circ} \mathrm{C}$ at least one week before further experimentation. The obtained suspension of PVA-coated SPIONs was called PVA-SPIONs.

2.4.PVA-SPIONs@Silica-Amino Synthesis. Silica-coated PVASPIONs with or without amino groups were synthesized as described below. A $1 \mathrm{~mL}$ quantity of PVA-SPIONs (at $5 \mathrm{mg}_{\mathrm{Fe}} / \mathrm{mL}$ ) was mixed with $36 \mathrm{~mL}$ of ethanol. Then, either $375 \mu \mathrm{L}$ of TEOS (volume ratio TEOS/APTES: 4/0) or $281 \mu \mathrm{L}$ of TEOS and $94 \mu \mathrm{L}$ of APTES (volume ratio TEOS/APTES: 3/1) were added to obtain only silica-coated PVA-SPIONs or silica-coated PVA-SPIONs with amino groups, respectively. Next, $4 \mathrm{~mL}$ of $28 \%$ ammonia $\left(\mathrm{NH}_{4} \mathrm{OH}\right)$ was added to the suspension, which was mixed for $90 \mathrm{~min}$. The suspensions were then washed 3 times with $30 \mathrm{~min}$ of centrifugation at $30000 \mathrm{~g}$ using water. The particles were then redispersed in $10 \mathrm{~mL}$ of water at a concentration of $0.5 \mathrm{mg}_{\mathrm{Fe}} / \mathrm{mL}$ and characterized. The particles were called PVA-SPIONs@silica andPVA-SPIONs@silica-amino, respectively.

2.5. Chemical Characterizations. PVA-SPIONs and PVASPIONs@Silica-(Amino) were observed on a CM12 transmission electron microscope (TEM) at $100 \mathrm{kV}$ (FEI Co. Philips Electron Optics, Zürich, Switzerland), where their mean diameters $\left(d_{\text {TEM }}\right)$ were measured using at least 400 particles. The hydrodynamic diameters weighted in number $\left(d_{H}\right)$ and Zeta potential $(\zeta$ potential calculated from Smoluchowski approximation) were measured on a Zetasizer from Malvern Instruments (software version: 5.2$)$ at around $\mathrm{pH} 7(7 \pm 1)$.

The NP concentrations ([NP] in $\mathrm{mg}_{\mathrm{NP}} / \mathrm{mL}$ ) were calculated by determining the mass of $3 \mathrm{~mL}$ of freeze-dried nanoparticles and dividing this mass by three. The iron concentration ( $[\mathrm{Fe}]$ in $\mathrm{mg}_{\mathrm{Fe}} / \mathrm{mL}$ ) was measured using a magnetic susceptometer (MS3 from Bartington) following a protocol described elsewhere [42]. For the PVA-SPIONs@silica-amino particles, the amounts of silicon $\left([\mathrm{Si}]\right.$ in $\mathrm{mg}_{\mathrm{Si}} / \mathrm{mL}$ ) were measured using induced coupled plasma atomic emission spectroscopy measurements (ICP-OES: ICPE-9000 Shimadzu) of nanoparticles dissolved in a $\mathrm{NaOH} 2 \mathrm{M}$ solution. The amount of PVA still present was calculated after thermogravimetric analyses (TGA: Mettler Toledo TGA/SDTA 851e). A few milligrams of these powders were analyzed using TGA. The loss of mass from $150^{\circ} \mathrm{C}$ to $800^{\circ} \mathrm{C}$ under an air condition at $30 \mathrm{~mL} / \mathrm{min}$ (with a heating rate of $10^{\circ} \mathrm{C} / \mathrm{min}$ ) was used for the calculation of the PVA loss $\left(\%_{\mathrm{PVA}}\right)$ because all the PVA burned above $150^{\circ} \mathrm{C}$ and below $800^{\circ} \mathrm{C}$ under the same conditions (Figure 1). With this measurement, combined with the iron concentration $\left([\mathrm{Fe}]\right.$ in $\left.\mathrm{mg}_{\mathrm{Fe}} / \mathrm{mL}\right)$, the final mass ratio of PVA/Fe was calculated using the following equation:

$$
\frac{\mathrm{PVA}}{\mathrm{Fe}}=\frac{\%_{\mathrm{PVA}} \cdot[\mathrm{NP}]}{[\mathrm{Fe}]} \text {. }
$$

\section{Results and Discussion}

The two types of silica/PVA-SPION core/shell nanoparticles showed approximately the same shape and morphology (Figure 2). They look like "raspberry-like" nanoparticles due to the cross-linking effect of the silica precursors and the $\mathrm{OH}$ 
TABLE 1: Sizes and Zeta potentials of PVA-coated SPIONs with and without silica shells, with PVA-SPIONs given as reference.

\begin{tabular}{|c|c|c|c|c|}
\hline Nanoparticles & Production ( $\mathrm{g}_{\mathrm{NP}} /$ batch $)$ & $d_{\mathrm{TEM}}(\mathrm{nm})$ & $d_{H}(\mathrm{~nm})$ & $\zeta$ potential $(\mathrm{mV})$ \\
\hline PVA-SPIONs & 60 & $7 \pm 2$ & $30 \pm 3$ & $+20 \pm 2$ \\
\hline PVA-SPIONs@silica & 2.6 & $48 \pm 10$ & $142 \pm 53$ & $-34 \pm 5$ \\
\hline PVA-SPIONs@silica-amino & 2.6 & $47 \pm 9$ & $145 \pm 60$ & $+20 \pm 4$ \\
\hline
\end{tabular}

TABLE 2: Chemical characterizations of PVA-coated SPIONs with and without silica shells, with PVA-SPIONs given as reference.

\begin{tabular}{lccccccc}
\hline Nanoparticles & {$[\mathrm{NP}]\left(\mathrm{mg}_{\mathrm{NP}} / \mathrm{mL}\right)$} & {$[\mathrm{Fe}]\left(\mathrm{mg}_{\mathrm{Fe}} / \mathrm{mL}\right)$} & {$[\mathrm{NP}] /[\mathrm{Fe}]$} & {$[\mathrm{Si}]\left(\mathrm{mg}_{\mathrm{Si}} / \mathrm{mL}\right)$} & {$[\mathrm{Si}] /[\mathrm{Fe}]$} & Loss of PVA & PVA/Fe ratio \\
\hline PVA-SPIONs & 43 & 5 & 8.6 & 0 & 0 & $84 \%$ & 9.0 \\
PVA-SPIONs@silica & 8 & 0.54 & 14.8 & 3.35 & 6.2 & $13 \%$ & 1.9 \\
PVA-SPIONs@silica-amino & 6.8 & 0.45 & 15.1 & 1.76 & 3.9 & $20 \%$ & 3.0 \\
\hline
\end{tabular}

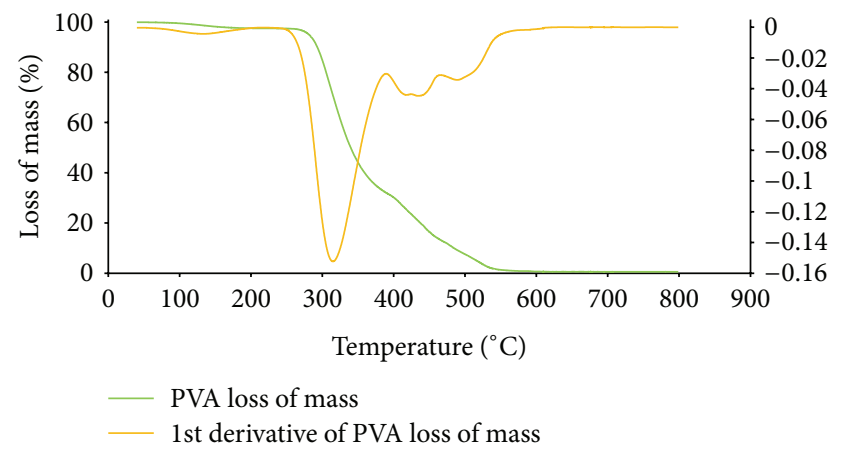

FIGURE 1: Loss of mass and its first derivative as function of temperature of $\mathrm{PVA}-\mathrm{OH}$ under air at $30 \mathrm{~mL} / \mathrm{min}$ and heating rate of $10^{\circ} \mathrm{C} / \mathrm{min}$.

groups of PVA and SPIONs [39]. They were stable for more than 2 months in water and biological buffers such as sodium chloride solution at $0.15 \mathrm{M}$ or diluted phosphate buffer saline solution (PBS at 1X). The two synthesis methods allowed for a good reproducibility and easy scale-up. With this method, one synthesis batch allowed for the production of almost $3 \mathrm{~g}$ of nanoparticles (Table 1).

The TEM sizes were around $50 \mathrm{~nm}$ for both PVASPIONs@silica. Their hydrodynamic diameters of around $140 \mathrm{~nm}\left(d_{H}\right.$ in Table 1$)$ were different from the TEM observation, proving the possible agglomeration of the NPs under water conditions, in addition to the water monolayer measured by this method. The Zeta potential of the PVASPIONs@silica was negative at pH 7 (-35 mV), whereas it was positive $(+20 \mathrm{mV})$ for the PVA-SPIONs@silica-amino. These first characterizations proved that the grafting of the APTES was efficient because it successfully coated the NPs with amino groups, which was proven by the switch in the Zeta potential from negative to positive values. In addition APTES did not influence the sizes and morphologies of the NPs.

APTES seemed to have some influence on the chemical composition (Table 2). The concentrations of NPs ([NP]) and iron $([\mathrm{Fe}])$ were proportional with or without the addition of APTES. The $[\mathrm{NP}] /[\mathrm{Fe}]$ ratios were 14.8 and 15.1 , respectively, for the PVA-SPIONs@silica and PVA-SPIONs@silica-amino, indicating that APTES did not influence the concentration of iron in the NPs. However, the chemical compositions differed regarding the silicon and PVA contents (Table 2). With APTES, the quantity of silicon was much lower compared to the NPs synthesized without APTES, shifting the $[\mathrm{Si}] /[\mathrm{Fe}]$ ratio from 6.2 to 3.9. This observation can be explained by the lower amount of TEOS used to obtain the PVASPIONs@silica-amino ( $281 \mu \mathrm{L}$ instead of $375 \mu \mathrm{L}$ with only the TEOS precursor). Because APTES is usually known to form only a monolayer of silica $[43,44]$, it could be normal to find less silicon with the combination of the two silica precursors than with the use of only the "normal" silica precursor.

Furthermore, the NPs with APTES had a higher amount of PVA. As shown in Figure 3, the quantity of PVA still present in the PVA-SPIONs@silica-amino is much higher than that present in PVA-SPIONs@silica,with mass losses of $20 \%$ and $13 \%$, respectively. Thus, the PVA/Fe ratio passed from 1.9 to 3.0 without and with APTES during the reaction (Table 2). APTES combined with TEOS seemed to improve the quantity of cross-linked PVA on the SPIONs [39]. This observation could be due to the different reactivity behaviors of the alkoxy chemical groups present in the two silica precursors, which were certainly influenced by their chemical environment [45]. It could be possible that the ethoxy groups of APTES interacted more with the hydroxyls groups of the PVA, leading to a better cross-linking of this polymer and SPIONs with silica. This hypothesis correlates with the observation of the higher PVA/Fe final ratio.

\section{Conclusion}

Combining amino-functionalized and classical silica precursors with PVA-SPIONs appeared to be an interesting and promising solution to obtain, in one step, silica/iron oxide core/shell NPs with covalently bonded PVA and amino groups. The original shape observed as a result of the crosslinking of the PVA and SPIONs with the silica also allowed reproducibility and easy scale-up of the synthesis. APTES decreased the quantity of silicon needed to obtain the same shape and morphology as the PVA-SPIONs@silica. It also significantly increased the presence of PVA found inside the silica beads. 


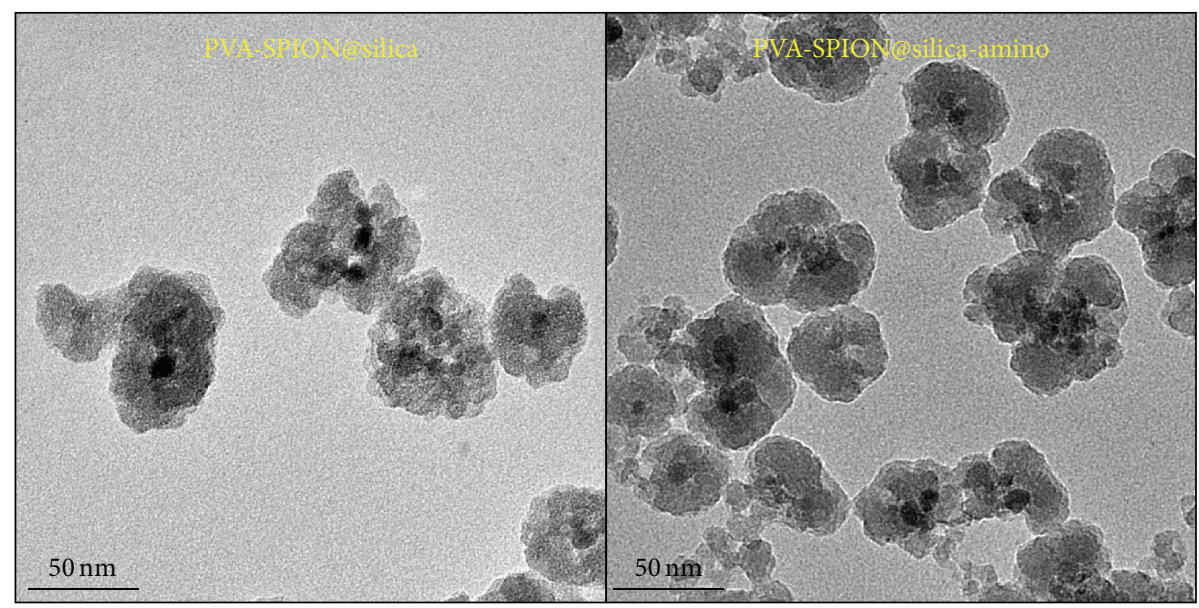

FIGURE 2: TEM pictures of PVA-SPIONs@silica and PVA-SPIONs@silica-amino.

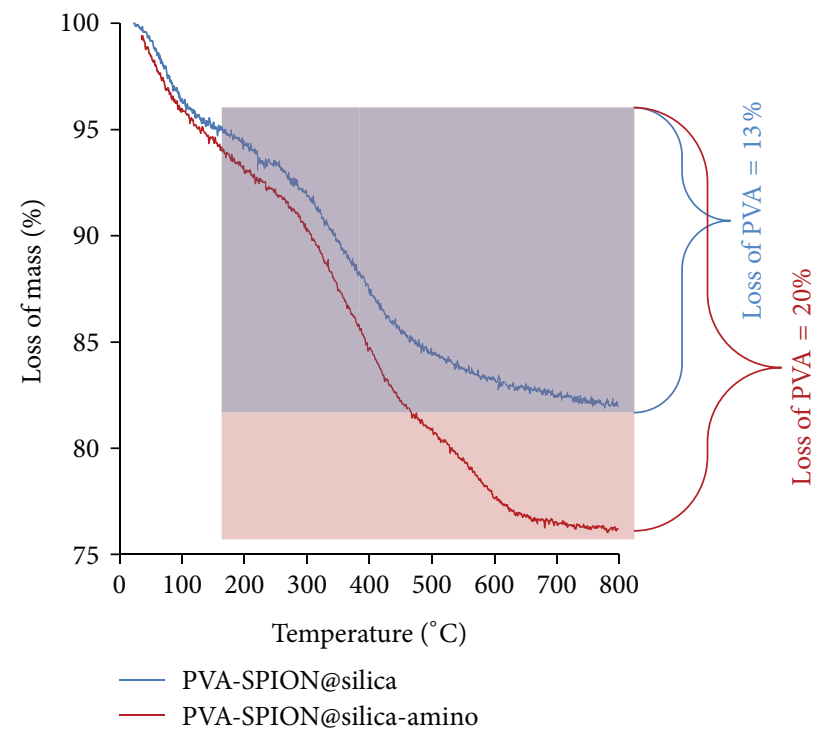

FIGURE 3: Thermogravimetric analyses of PVA-SPIONs@silica and PVA-SPIONs@silica-amino: loss of mass from $150^{\circ} \mathrm{C}$ to $800^{\circ} \mathrm{C}$ corresponds to loss of mass of PVA contained in silica beads.

This synthesis method combined the advantages of the PVA stabilization and the shape and processing control of silica encapsulation. Optimizing the APTES/TEOS ratio as well as the temperature of the reaction could be a way to continue improving this original route to graft PVA onto SPIONs. Furthermore, precoating oxide nanoparticles with PVA and then using a classical sol-gel route to encapsulate them in silica shells is an interesting and promising method to develop biocompatible nanoparticles for industrialized nanomedicine.

\section{Conflict of Interests}

The authors declare that there is no conflict of interests regarding the publication of this paper.

\section{Acknowledgment}

This work has been supported by the NanoDiaRA Project, through Grant agreement no. 228929, funded by the EC Seventh Framework Program FP7-NMP-2008-L.

\section{References}

[1] A. M. Prodan, S. L. Iconaru, C. S. Ciobanu, M. C. Chifiriuc, M. Stoicea, and D. Predoi, "Iron oxide magnetic nanoparticles: characterization and toxicity evaluation by in vitro and in vivo assays," Journal of Nanomaterials, vol. 2013, Article ID 587021, 10 pages, 2013.

[2] M. Mahmoudi, A. Simchi, A. S. Milani, and P. Stroeve, "Cell toxicity of superparamagnetic iron oxide nanoparticles," Journal of Colloid and Interface Science, vol. 336, no. 2, pp. 510-518, 2009.

[3] S. K. Yen, D. Jańczewski, J. L. Lakshmi et al., "Design and synthesis of polymer-functionalized NIR fluorescent dyes-magnetic nanoparticles for bioimaging," ACS Nano, vol. 7, no. 8, pp. 67966805, 2013.

[4] J. R. McCarthy and R. Weissleder, "Multifunctional magnetic nanoparticles for targeted imaging and therapy," Advanced Drug Delivery Reviews, vol. 60, no. 11, pp. 1241-1251, 2008.

[5] L. Maurizi, A. Papa, L. Dumont et al., "Influence of surface charge and polymer coating on internalization and biodistribution of polyethylene glycol-modified iron oxide nanoparticles," Journal of Biomedical Nanotechnology, vol. 11, no. 1, pp. 126-136, 2015.

[6] F. Schulze, A. Dienelt, S. Geissler et al., "Amino-polyvinyl alcohol coated superparamagnetic iron oxide nanoparticles are suitable for monitoring of human mesenchymal stromal cells in vivo," Small, vol. 10, no. 21, pp. 4340-4351, 2014.

[7] Y. Chen, A. Bose, and G. D. Bothun, "Controlled release from bilayer-decorated magnetoliposomes via electromagnetic heating," ACS Nano, vol. 4, no. 6, pp. 3215-3221, 2010.

[8] H. Markides, M. Rotherham, and A. J. El Haj, "Biocompatibility and toxicity of magnetic nanoparticles in regenerative medicine," Journal of Nanomaterials, vol. 2012, Article ID 614094, 11 pages, 2012.

[9] L. Maurizi, F. Bouyer, J. Paris, F. Demoisson, L. Saviot, and N. Millot, "One step continuous hydrothermal synthesis of very 
fine stabilized superparamagnetic nanoparticles of magnetite," Chemical Communications, vol. 47, no. 42, pp. 11706-11708, 2011.

[10] C. Sun, K. Du, C. Fang et al., "PEG-mediated synthesis of highly dispersive multifunctional superparamagnetic nanoparticles: their physicochemical properties and function in vivo," $A C S$ Nano, vol. 4, no. 4, pp. 2402-2410, 2010.

[11] L. Maurizi, H. Bisht, F. Bouyer, and N. Millot, "Easy route to functionalize iron oxide nanoparticles via long-term stable thiol groups," Langmuir, vol. 25, no. 16, pp. 8857-8859, 2009.

[12] B. Basly, D. Felder-Flesch, P. Perriat et al., "Dendronized iron oxide nanoparticles as contrast agents for MRI," Chemical Communications, vol. 46, no. 6, pp. 985-987, 2010.

[13] U. Sakulkhu, L. Maurizi, M. Mahmoudi et al., "Ex situ evaluation of the composition of protein corona of intravenously injected superparamagnetic nanoparticles in rats," Nanoscale, vol. 6, no. 19, pp. 11439-11450, 2014.

[14] A. K. Gupta and M. Gupta, "Synthesis and surface engineering of iron oxide nanoparticles for biomedical applications," Biomaterials, vol. 26, no. 18, pp. 3995-4021, 2005.

[15] M. Mahmoudi, S. Sant, B. Wang, S. Laurent, and T. Sen, "Superparamagnetic iron oxide nanoparticles (SPIONs): development, surface modification and applications in chemotherapy," Advanced Drug Delivery Reviews, vol. 63, no. 1-2, pp. 2446, 2011.

[16] N. Desai, "Challenges in development of nanoparticle-based therapeutics," The AAPS Journal, vol. 14, no. 2, pp. 282-295, 2012.

[17] R. Paliwal, R. J. Babu, and S. Palakurthi, "Nanomedicine scaleup technologies: feasibilities and challenges," AAPS PharmSciTech, vol. 15, no. 6, pp. 1527-1534, 2014.

[18] L. Maurizi, F. Bouyer, M. Ariane, R. Chassagnon, and N. Millot, "Fast and continuous synthesis of nanostructured iron spinel in supercritical water: influence of cations and citrates," RSC Advances, vol. 4, no. 86, pp. 45673-45678, 2014.

[19] C. Leduc, S. Si, J. Gautier et al., "A highly specific gold nanoprobe for live-cell single-molecule imaging," Nano Letters, vol. 13, no. 4, pp. 1489-1494, 2013.

[20] M. Chastellain, A. Petri, and H. Hofmann, "Particle size investigations of a multistep synthesis of PVA coated superparamagnetic nanoparticles," Journal of Colloid and Interface Science, vol. 278, no. 2, pp. 353-360, 2004.

[21] K. Schulze, A. Koch, A. Petri-Fink et al., "Uptake and biocompatibility of functionalized poly(vinylalcohol) coated superparamagnetic maghemite nanoparticles by synoviocytes in vitro," Journal of Nanoscience and Nanotechnology, vol. 6, no. 910, pp. 2829-2840, 2006.

[22] Y. Jiang, A. Schädlich, E. Amado et al., "In-vivo studies on intraperitoneally administrated poly(vinyl alcohol)," Journal of Biomedical Materials Research-Part B Applied Biomaterials, vol. 93, no. 1, pp. 275-284, 2010.

[23] Y. Kaneo, S. Hashihama, A. Kakinoki, T. Tanaka, T. Nakano, and Y. Ikeda, "Pharmacokinetics and biodisposition of poly(vinyl alcohol) in rats and mice," Drug metabolism and pharmacokinetics, vol. 20, no. 6, pp. 435-442, 2005.

[24] N. Aguiló-Aguayo, L. Maurizi, S. Galmarini et al., "Aqueous stabilisation of carbon-encapsulated superparamagnetic $\alpha$-iron nanoparticles for biomedical applications," Dalton Transactions, vol. 43, no. 36, pp. 13764-13775, 2014.

[25] U. Sakulkhu, M. Mahmoudi, L. Maurizi, J. Salaklang, and H. Hofmann, "Protein corona composition of superparamagnetic iron oxide nanoparticles with various physico-Chemical properties and coatings," Scientific Reports, vol. 4, article 5020, 2014.
[26] T. J. Brunner, P. Wick, P. Manser et al., "In vitro cytotoxicity of oxide nanoparticles: comparison to asbestos, silica, and the effect of particle solubility," Environmental Science \& Technology, vol. 40, no. 14, pp. 4374-4381, 2006.

[27] M. Liong, J. Lu, M. Kovochich et al., "Multifunctional inorganic nanoparticles for imaging, targeting, and drug delivery," ACS Nano, vol. 2, no. 5, pp. 889-896, 2008.

[28] A.-H. Lu, E. L. Salabas, and F. Schüth, "Magnetic nanoparticles: synthesis, protection, functionalization, and application," Angewandte Chemie - International Edition, vol. 46, no. 8, pp. 1222 1244, 2007.

[29] U. Sakulkhu, M. Mahmoudi, L. Maurizi et al., "Significance of surface charge and shell material of superparamagnetic iron oxide nanoparticle (SPION) based core/shell nanoparticles on the composition of the protein corona," Biomater. Sci., vol. 3, no. 2, pp. 265-278, 2015.

[30] Y. Chen and Y. Zhang, "Fluorescent quantification of amino groups on silica nanoparticle surfaces," Analytical and Bioanalytical Chemistry, vol. 399, no. 7, pp. 2503-2509, 2011.

[31] S. Kralj, M. Drofenik, and D. Makovec, "Controlled surface functionalization of silica-coated magnetic nanoparticles with terminal amino and carboxyl groups," Journal of Nanoparticle Research, vol. 13, no. 7, pp. 2829-2841, 2011.

[32] P. Ashtari, X. He, K. Wang, and P. Gong, "An efficient method for recovery of target ssDNA based on amino-modified silicacoated magnetic nanoparticles," Talanta, vol. 67, no. 3, pp. 548554, 2005.

[33] P. Tartaj, T. González-Carreño, and C. J. Serna, "Single-step nanoengineering of silica coated maghemite hollow spheres with tunable magnetic properties," Advanced Materials, vol. 13, no. 21, pp. 1620-1624, 2001.

[34] D. Langevin, "Micelles and microemulsions," Annual Review of Physical Chemistry, vol. 43, no. 1, pp. 341-369, 1992.

[35] B. K. Paul and S. P. Moulik, "Uses and applications of microemulsions," Current Science, vol. 80, no. 8, pp. 990-1001, 2001.

[36] H. Wang, X. Zhu, L. Tsarkova, A. Pich, and M. Möller, "All-silica colloidosomes with a particle-bilayer shell," ACS Nano, vol. 5, no. 5, pp. 3937-3942, 2011.

[37] S. Laurent, D. Forge, M. Port et al., "Magnetic iron oxide nanoparticles: synthesis, stabilization, vectorization, physicochemical characterizations and biological applications," Chemical Reviews, vol. 108, no. 6, pp. 2064-2110, 2008.

[38] W. Stöber, A. Fink, and E. Bohn, "Controlled growth of monodisperse silica spheres in the micron size range," Journal of Colloid And Interface Science, vol. 26, no. 1, pp. 62-69, 1968.

[39] L. Maurizi, U. Sakulkhu, L. A. Crowe et al., "Syntheses of cross-linked polymeric superparamagnetic beads with tunable properties," RSC Advances, vol. 4, no. 22, pp. 11142-11146, 2014.

[40] A. Petri-Fink, M. Chastellain, L. Juillerat-Jeanneret, A. Ferrari, and H. Hofmann, "Development of functionalized superparamagnetic iron oxide nanoparticles for interaction with human cancer cells," Biomaterials, vol. 26, no. 15, pp. 2685-2694, 2005.

[41] R. Massart, "Preparation of aqueous magnetic liquids in alkaline and acidic media," IEEE Transactions on Magnetics, vol. 17, no. 2, pp. 1247-1248, 1981.

[42] L. Maurizi, U. Sakulkhu, A. Gramoun, J.-P. Vallee, and H. Hofmann, "A fast and reproducible method to quantify magnetic nanoparticle biodistribution," Analyst, vol. 139, no. 5, pp. 11841191, 2014. 
[43] S. Kralj, D. Makovec, S. Čampelj, and M. Drofenik, "Producing ultra-thin silica coatings on iron-oxide nanoparticles to improve their surface reactivity," Journal of Magnetism and Magnetic Materials, vol. 322, no. 13, pp. 1847-1853, 2010.

[44] S. Čampelj, D. Makovec, and M. Drofenik, "Functionalization of magnetic nanoparticles with 3-aminopropyl silane," Journal of Magnetism and Magnetic Materials, vol. 321, no. 10, pp. 13461350, 2009.

[45] B. Arkles, J. Steinmetz, J. Zazyczny, and P. Mehta, "Factors contributing to the stability of alkoxysilanes in aqueous solution," Journal of Adhesion Science and Technology, vol. 6, no. 1, pp. 193206, 1992. 

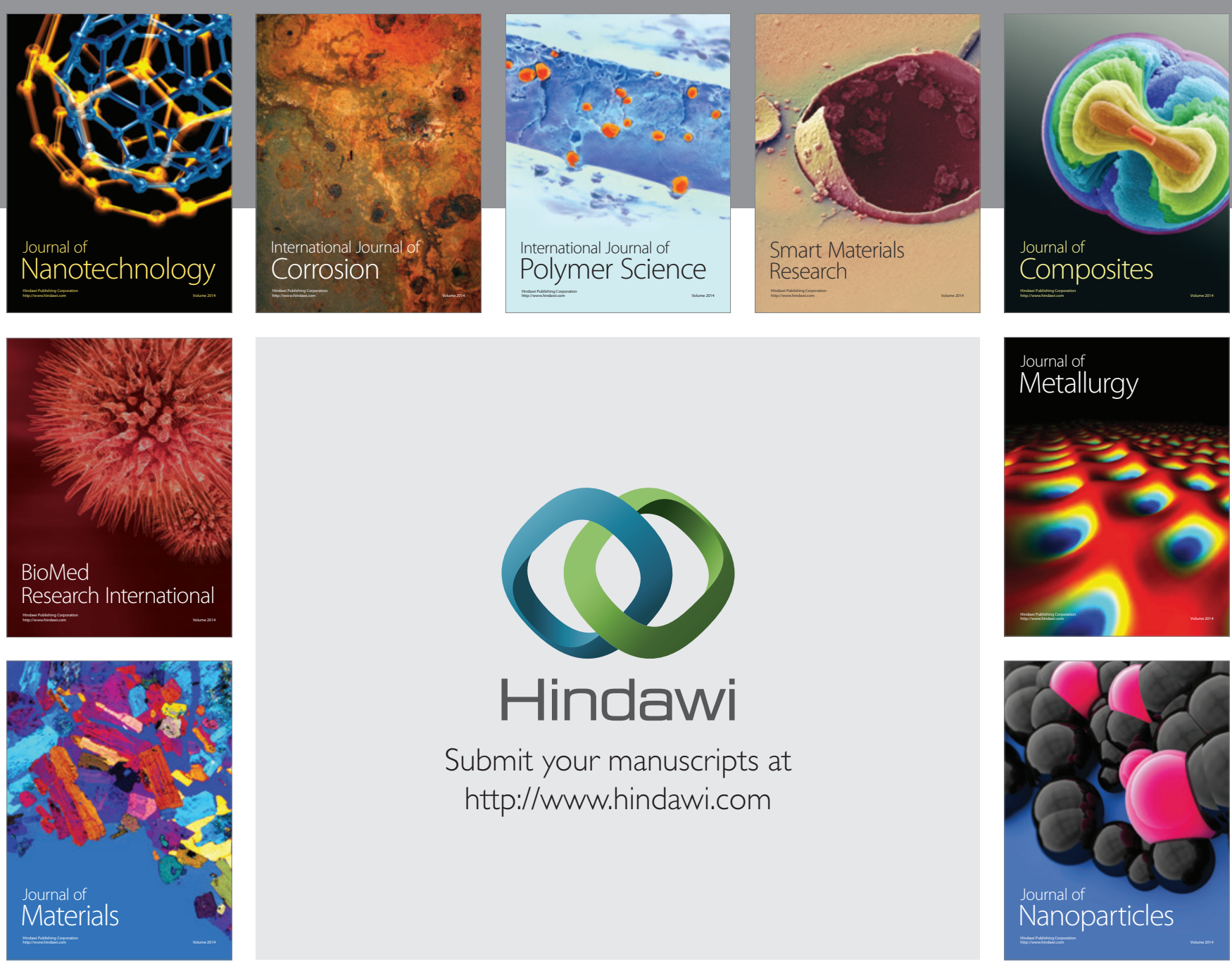

Submit your manuscripts at http://www.hindawi.com
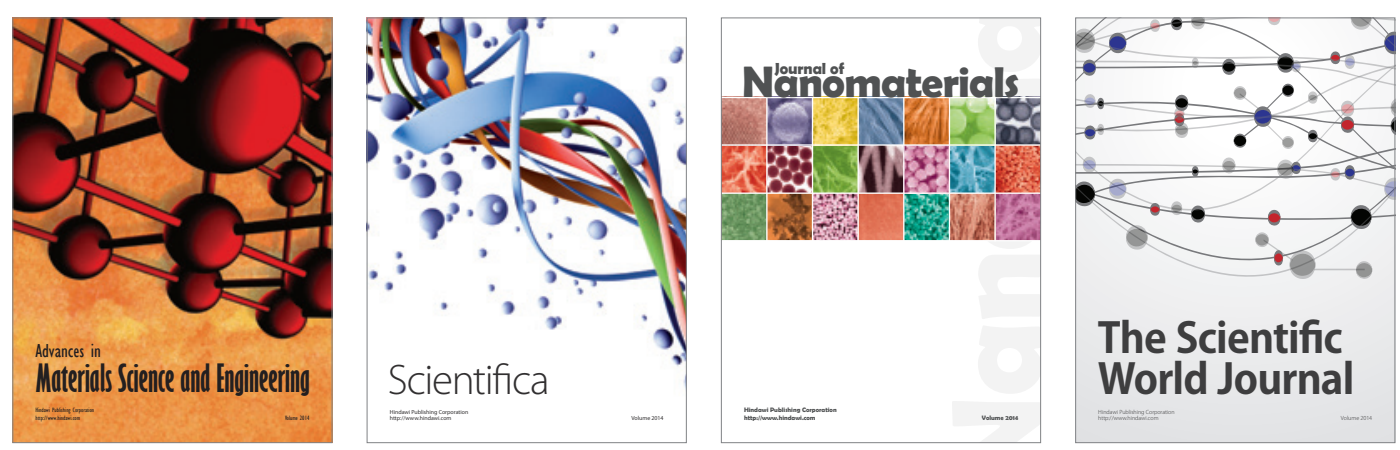

\section{The Scientific World Journal}
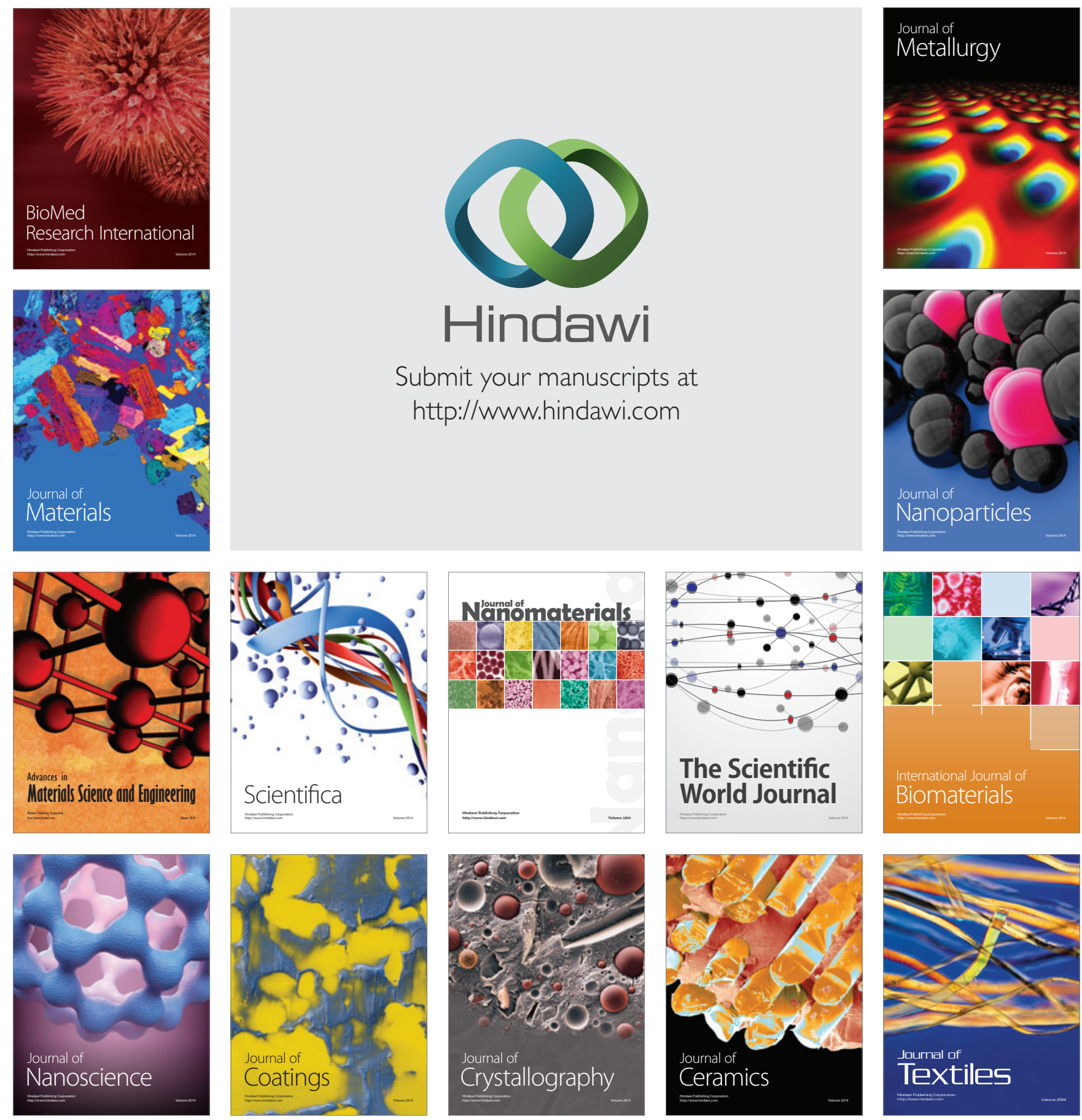